\title{
Nonlinear Viscoelastic-Plastic Creep Model of Rock Based on Fractional Calculus
}

\author{
Erjian Wei, ${ }^{1,2}$ Bin Hu $\mathbb{D}^{1,2}$ Jing Li ${ }^{10},{ }^{1,2}$ Kai Cui, ${ }^{1,2}$ Zhen Zhang, ${ }^{1,2}$ Aneng Cui, ${ }^{1,2}$ \\ and Liyao $\mathrm{Ma}^{1,2}$ \\ ${ }^{1}$ School of Resources and Environmental Engineering, Wuhan University of Science and Technology, Wuhan, Hubei, China \\ ${ }^{2}$ Hubei Key Laboratory for Efficient Utilization and Agglomeration of Metallurgic Mineral Resources, Wuhan, Hubei, China \\ Correspondence should be addressed to Bin Hu; hbin74@wust.edu.cn and Jing Li; lijing1994@wust.edu.cn
}

Received 6 December 2021; Accepted 28 December 2021; Published 13 January 2022

Academic Editor: Bing Bai

Copyright (c) 2022 Erjian Wei et al. This is an open access article distributed under the Creative Commons Attribution License, which permits unrestricted use, distribution, and reproduction in any medium, provided the original work is properly cited.

\begin{abstract}
A rock creep constitutive model is the core content of rock rheological mechanics theory and is of great significance for studying the long-term stability of engineering. Most of the creep models constructed in previous studies have complex types and many parameters. Based on fractional calculus theory, this paper explores the creep curve characteristics of the creep elements with the fractional order change, constructs a nonlinear viscoelastic-plastic creep model of rock based on fractional calculus, and deduces the creep constitutive equation. By using a user-defined function fitting tool of the Origin software and the Levenberg-Marquardt optimization algorithm, the creep test data are fitted and compared. The fitting curve is in good agreement with the experimental data, which shows the rationality and applicability of the proposed nonlinear viscoelastic-plastic creep model. Through sensitivity analysis of the fractional order $\beta_{2}$ and viscoelastic coefficient $\xi_{2}$, the influence of these creep parameters on rock creep is clarified. The research results show that the nonlinear viscoelastic-plastic creep model of rock based on fractional calculus constructed in this paper can well describe the creep characteristics of rock, and this model has certain theoretical significance and engineering application value for long-term engineering stability research.
\end{abstract}

\section{Introduction}

Rock rheology is a process in which the rock mineral structure is constantly adjusted with time, resulting in the continuous change of stress and strain state with time [1-7]. The rheological effect of rock is obvious in slope, tunnel, roadway, and other projects, which is a very important feature of rock materials [8-13]. A large number of engineering practices show that the long-term stability of a project is closely related to the rheological properties of rock [14-17]. Rock creep is an important part of rock rheological mechanics theory, and research on rock creep constitutive models is the core content of the theory [18-21]. Therefore, research on rock creep constitutive models will have very important theoretical significance and practical engineering value.

Many scholars have carried out research on rock creep constitutive models and have achieved fruitful research results. Xu et al. [22] proposed a nonlinear viscoplastic body (NVPB) and connected it with a five-element linear model to establish a famous river-sea model. Xia et al. [23] established a unified rheological mechanical model including 15 rheological mechanical properties. Based on the rheological damage degradation effect of rock masses, Zhang et al. [24] established a creep damage constitutive model with variable parameters. Wang et al. [25] proposed a nonlinear viscoelastic-plastic rheological model of the damage effect of drywet cycles on rock. Hu et al. [26] proposed a reversible nonlinear viscoelastic model (RNVE) to describe the recoverable viscoelastic response. The creep models established by the above researchers have achieved good results in describing the rheological characteristics of rock at various stages. However, some models have complex structures and a large number of elements, which increase the number of parameters and are unfavorable for engineering promotion. Therefore, seeking a creep model that can be composed of 
fewer elements has become a goal pursued by many rock rheological constitutive model researchers. Yin et al. [27] proposed a soft element based on fractional calculus theory, which provides a way to build a creep model with fewer elements. Based on fractional calculus theory and damage variables, Chen et al. [28] proposed a creep constitutive model to describe the time-varying damage characteristics of marble in the Jinping II hydropower station. Liu et al. [29] established the Burgers creep model based on fractional order. Based on fractional order theory, Liao et al. [30] established a nonlinear creep model of warm frozen silt under three-dimensional stress conditions. Gao et al. [31] established a variable fractional rheological model to describe the whole-stage creep behavior of rock and further discussed the physical significance of fractional order. Huang et al. [32] introduced the relationship between the fractional viscosity coefficient and stress to describe the nonlinear relationship of creep strain increase in each stage. By establishing the relationship between a damage variable and the initial damage, the creep model of the acceleration stage was improved. Xiang et al. [33] introduced the Almeida fractional derivative into the elasticviscoplastic model of soft soil, established a new fractional creep model, and analyzed and determined the kernel function with the best performance of the model. Peng et al. [34] derived the creep compliance of a fractional constitutive model and established a wellbore creep model including the drilling pressure process. Xu and Jiang [35] used an interior point algorithm to solve the corresponding nonlinear optimization constraint problem and studied the fractional order constitutive relation model represented by a fractional element network.

The above research can well apply fractional calculus theory to the construction of rock creep models, but the fractional creep element is not discussed in depth. In this paper, by discussing the influence of the change in fractional order on the creep characteristic curve of rock, creep elements of different orders are innovatively used to construct a nonlinear viscoelastic-plastic creep model of rock, and a nonlinear creep model of rock with fewer parameters is developed using fewer elements. On this basis, the creep test results are nonlinearly fitted to verify the rationality and applicability of the constructed model.

\section{Creep Element Based on Fractional Calculus}

Usually, calculus is a positive integer derivative and integral, and fractional calculus is a mathematical method used to study the properties and applications of differential and integral operators of arbitrary order. Fractional calculus has many forms, such as the Grunwald-Letnikov (GL) type, Riemann-Liouville (RL) type, Caputo type, and Weyl type fractional calculus, among which the RL type is widely used. This paper uses the Riemann-Liouville theory $[27,36]$ and defines a $\beta$-order integral of the function $f(t)$ as

$$
\frac{\mathrm{d}^{-\beta} f(t)}{\mathrm{d} t^{-\beta}}={ }_{0} D_{t}^{-\beta} f(t)=\int_{0}^{t} \frac{(t-\tau)^{\beta-1}}{\Gamma(\beta)} f(\tau) \mathrm{d} \tau .
$$

The fractional differential is defined as

$$
\frac{\mathrm{d}^{\beta} f(t)}{\mathrm{d} t^{\beta}}={ }_{0} D t_{\beta} f(t)=\frac{d^{n}}{\mathrm{~d} t^{n}}\left[{ }_{0} D t_{-(n-\beta)} f(t)\right] .
$$

In formulas (1) and (2), $\beta>0$ and $n-1<\beta \leq n$ ( $n$ is a positive integer); $\Gamma(\beta)$ is a gamma function defined as

$$
\Gamma(\beta)=\int_{0}^{\infty} \mathrm{e}^{-t} t^{\beta-1} \mathrm{~d} t(\operatorname{Re}(\beta)>0) .
$$

The Laplace transform of the fractional calculus is

$$
\left.\begin{array}{l}
L\left[{ }_{0} D_{t}^{-\beta} f(t), p\right]=p^{-\beta} f(p)(\beta>0) \\
L\left[{ }_{0} D_{t}^{\beta} f(t), p\right]=p^{\beta} f(p) \\
(f(t) \text { Integrable near by } t=0,0 \leq \beta \leq 1)
\end{array}\right\},
$$

where $\bar{f}(p)$ is the Laplace transform of $f(t)$.

The stress-strain relationship described by the fractional calculus is

$$
\sigma(t)=\xi \frac{\mathrm{d}^{\beta} \varepsilon(t)}{\mathrm{d} t^{\beta}} .
$$

Clearly, when $\beta=0$, it is the stress-strain relationship of an ideal solid, and when $\beta=1$, it is the stress-strain relationship of an ideal fluid. Therefore, when $0<\beta<1$, the state of matter can be described as between an ideal solid and ideal fluid. Scott-Blair called the mechanical element satisfying formula (5) a Scott-Blair element, as shown in Figure 1. This element is actually a two-parameter element containing $\xi$ and $\beta$, which can better reflect the nonlinear gradual process of rheological problems.

When the stress is constant, the element will describe the creep phenomenon, a Laplace transform is performed on both sides of formula (5) at the same time, and the following equation can be obtained:

$$
\bar{\varepsilon}(s)=\frac{\sigma_{0}}{\xi s^{\beta+1}} .
$$

For formula (6), the creep equation of the Scott-Blair element is obtained using a Laplace inverse transformation:

$$
\varepsilon(t)=\frac{\sigma}{\xi} \frac{t^{\beta}}{\Gamma(1+\beta)} .
$$

According to formula (7), the creep curves of different $\beta$ values under certain stresses can be drawn, as shown in Figure 2.

From the above diagram, when $\beta=0$, the strain is a certain value that reflects the strain characteristics of an ideal solid after a certain stress. When $\beta=1$, the strain increases linearly with time, which reflects the strain characteristics of an ideal fluid under a certain stress. When $0<\beta<1$, the strain increases greatly at the beginning and then slightly, while the strain rate decreases gradually to close to 0 and tends to be stable. At this time, the curve presents the characteristics of rock attenuation creep and steady-state creep. When $\beta>1$, the strain and strain rate increase rapidly, 


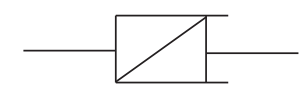

Figure 1: Diagram of the Scott-Blair element components.

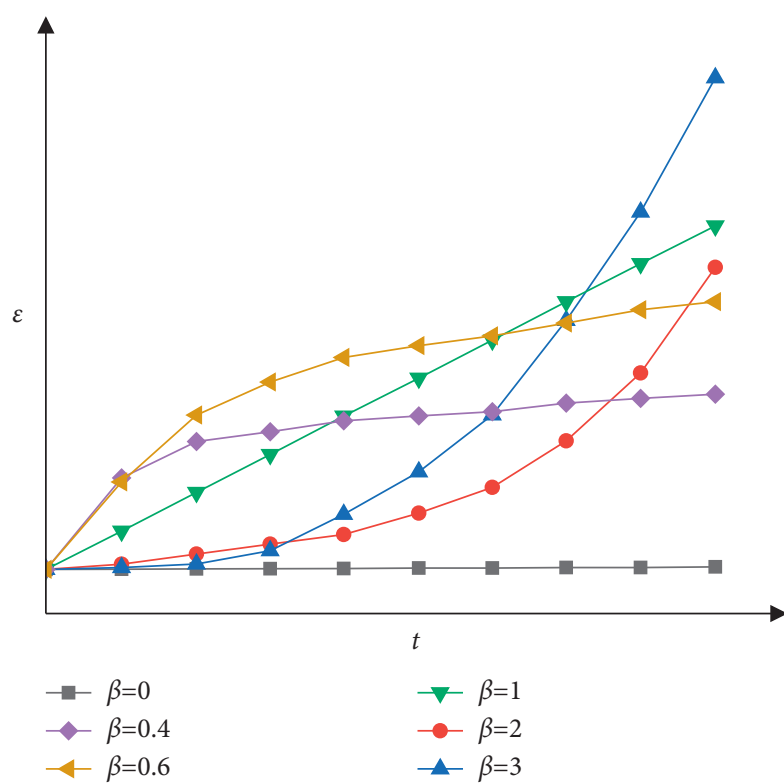

FIGURE 2: Variation characteristics of the strain with time under different $\beta$ values.

and the curve presents the characteristics of the accelerated creep stage of rock.

\section{Nonlinear Viscoelastic-Plastic Creep Model}

When the stress in rock is lower than its long-term strength, the rock generally experiences the two stages of decay creep and steady creep. In general, the Burgers model can describe the creep characteristics of rock at this time. As mentioned in the previous section, when $0<\beta<1$, the creep element can describe the material state between an ideal solid and ideal fluid, and it can be considered that the element is a composite element containing elastic elements and viscous elements; the Kelvin body in the Burgers model describes the viscoelastic characteristics of the rock, so we can consider that a creep element at $0<\beta<1$ can replace the Kelvin body in the Burgers model, which can not only describe the first two stages of rock creep similar to the Burgers model but also reduce the number of elements. When the stress in rock exceeds its long-term strength, the rock will enter the accelerated creep stage after experiencing the first two creep stages. From the analysis in the previous section, it can be seen that when $\beta>1$, rock creep presents the characteristics of the accelerated creep stage, so we can consider that the creep element when $\beta>1$ is used to describe the accelerated creep stage of rock. Therefore, we can construct a nonlinear viscoelastic-plastic creep model based on fractional calculus, as shown in Figure 3.

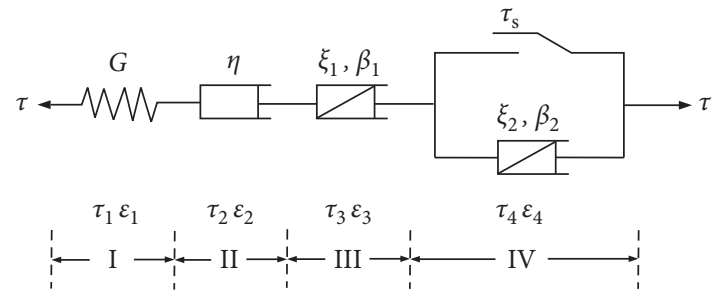

FIGURE 3: Schematic diagram of the rock nonlinear viscoelasticplastic creep model.

It can be seen from Figure 3 that when $\tau<\tau s$, I, II, and III are all involved in creep deformation. The state equations of the creep model are

$$
\begin{aligned}
& \tau=\tau_{1}=\tau_{2}=\tau_{3}, \\
& \varepsilon=\varepsilon_{1}+\varepsilon_{2}+\varepsilon_{3}, \\
& \tau_{1}=G \varepsilon_{1}, \\
& \tau_{2}=\eta \varepsilon_{2}, \\
& \tau_{3}=\xi_{1} \frac{\mathrm{d}^{\beta_{1}} \varepsilon_{3}(t)}{\mathrm{d} t^{\beta_{1}}} .
\end{aligned}
$$

From formula (10),

$$
\begin{aligned}
& \varepsilon_{1}=\frac{\tau_{1}}{G}, \\
& \varepsilon_{2}=\frac{\tau_{2}}{\eta} t, \\
& \varepsilon_{3}=\frac{\tau_{3}}{\xi_{1}} \frac{t^{\beta_{1}}}{\Gamma\left(\beta_{1}+1\right)} .
\end{aligned}
$$

From formulas (8), (9), and (11), we can get

$$
\varepsilon(t)=\frac{\tau}{G}+\frac{\tau}{\eta} t+\frac{\tau}{\xi_{1}} \frac{t^{\beta_{1}}}{\Gamma\left(\beta_{1}+1\right)} .
$$

Formula (12) is the creep equation of the rock nonlinear viscoelastic-plastic creep model when $\tau<\tau s$.

When $\tau \geq \tau s$, I, II, III, and IV all participate in creep deformation. The state equations of the creep model are

$$
\begin{aligned}
\tau & =\tau_{1}=\tau_{2}=\tau_{3}=\tau_{s}+\tau_{4}, \\
\varepsilon & =\varepsilon_{1}+\varepsilon_{2}+\varepsilon_{3}+\varepsilon_{4}, \\
\tau_{1} & =G \varepsilon_{1}, \\
\tau_{2} & =\eta \dot{\varepsilon_{2}}, \\
\tau_{3} & =\xi_{1} \frac{\mathrm{d}^{\beta_{1}} \varepsilon_{3}(t)}{\mathrm{d} t^{\beta_{1}}} \\
\tau_{4} & =\xi_{2} \frac{\mathrm{d}^{\beta_{2}} \varepsilon_{4}(t)}{\mathrm{d} t^{\beta_{2}}} .
\end{aligned}
$$


From formula (15),

$$
\begin{aligned}
& \varepsilon_{1}=\frac{\tau_{1}}{G}, \\
& \varepsilon_{2}=\frac{\tau_{2}}{\eta} t, \\
& \varepsilon_{3}=\frac{\tau_{3}}{\xi_{1}} \frac{t^{\beta_{1}}}{\Gamma\left(\beta_{1}+1\right)}, \\
& \varepsilon_{4}=\frac{\tau_{4}}{\xi_{2}} \frac{t^{\beta_{2}}}{\Gamma\left(\beta_{2}+1\right)} .
\end{aligned}
$$

From formulas (13), (14), and (16), we can get

$$
\varepsilon(t)=\frac{\tau}{G}+\frac{\tau}{\eta} t+\frac{\tau}{\xi_{1}} \frac{t^{\beta_{1}}}{\Gamma\left(\beta_{1}+1\right)}+\frac{\tau-\tau_{s}}{\xi_{2}} \frac{t^{\beta_{2}}}{\Gamma\left(\beta_{2}+1\right)} .
$$

Formula (17) is the creep equation of the rock nonlinear viscoelastic-plastic creep model when $\tau \geq \tau$ s.

\section{Verification of the Creep Model}

By fitting the creep equation derived in the above section to rock creep test data, the rationality and applicability of the model constructed in this paper can be verified. In this paper, the relevant data of Wang et al. [37] on the shear creep test of granite are used. In this test, a shear creep test of saturated granite subjected to $2.216 \mathrm{MPa}$ normal stress is carried out by applying shear stress in different grades. The applied shear stresses are $5.084 \mathrm{MPa}, 8.132 \mathrm{MPa}$, 11.180 MPa, 14.228 MPa, and 17.276 MPa. The shear creep test results of granite are shown in Figure 4.

To show the creep deformation more clearly under different shear stresses, the Boltzmann superposition principle is used to process the test data, and the results are shown in Figure 5.

Figure 5 shows that when the shear stress is small, the creep process of the granite only includes the decay creep stage and steady creep stage. When the shear stress is large, the creep process presents the three stages of complete rheology. Based on the test results, a user-defined function fitting tool of the Origin software was used. When $\tau<\tau$ s, the fitting function was as in formula (12). When $\tau \geq \tau$ s, the fitting function was as in formula (17). The Levenberg-Marquardt optimization algorithm was used to fit and analyze the creep test data of the granite under different shear stresses. The fitting curve is shown in Figure 6, and the creep model parameters, shown in Table 1 , are obtained by fitting.

It can be seen from Figure 6 that the creep test data of rock under various loads are in good agreement with the fitting curves, and the correlation coefficients in Table 1 are basically close to 1 , indicating that the nonlinear viscoelasticplastic creep model based on fractional calculus constructed in this paper can well describe the instantaneous deformation, decay creep stage, steady creep stage, and accelerated creep stage of rock and further illustrate the rationality and applicability of the model.

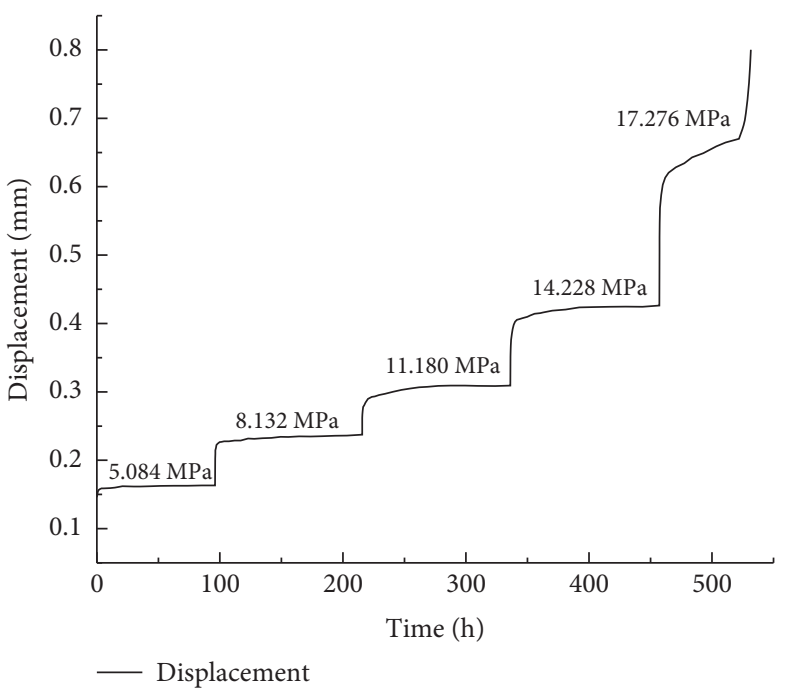

FiguRe 4: Shear creep test curve.

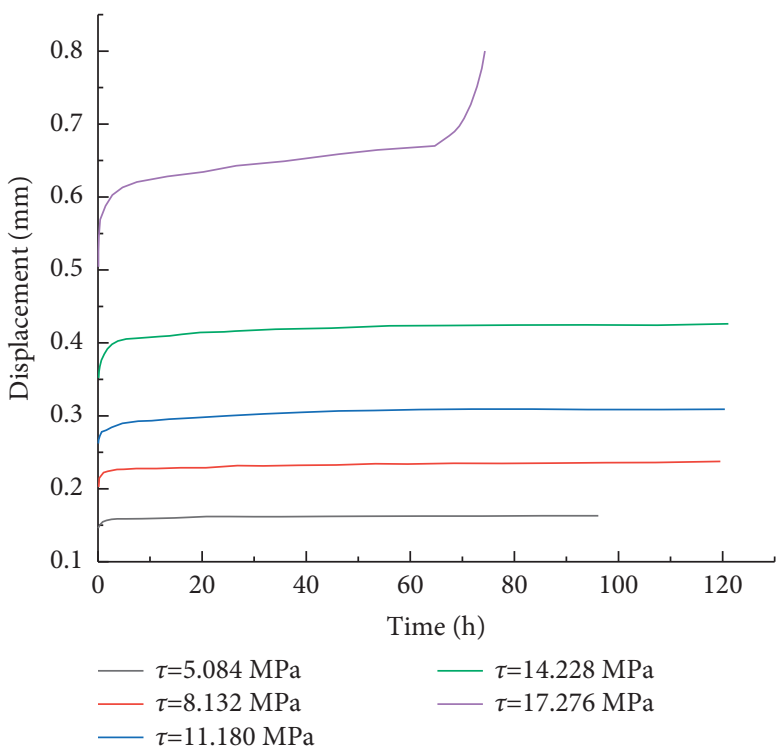

FIgURE 5: Test results after processing.

\section{Parameter Sensitivity Analysis}

Figures 7 and 8 show the parameter sensitivity analysis on the fractional order $\beta_{2}$ and viscoelastic coefficient $\xi_{2}$, respectively, and discuss their influence on the rock creep process. Specifically, when analyzing the parameter sensitivity of the fractional order $\beta_{2}$, the other model parameters use the values in Table 1, and the influence law is discussed by changing the value of the fractional order $\beta_{2}$. Figure 7 shows that with the increase in the fractional order $\beta_{2}$, the rock quickly enters viscoelastic-plastic deformation, and the rock creep enters the accelerated creep stage earlier. For the analysis of the parameter sensitivity of the viscoelastic coefficient $\xi_{2}$, the same method is used. The other model parameters use the values in Table 1. The influence law is discussed by changing the value of the viscoelastic coefficient 


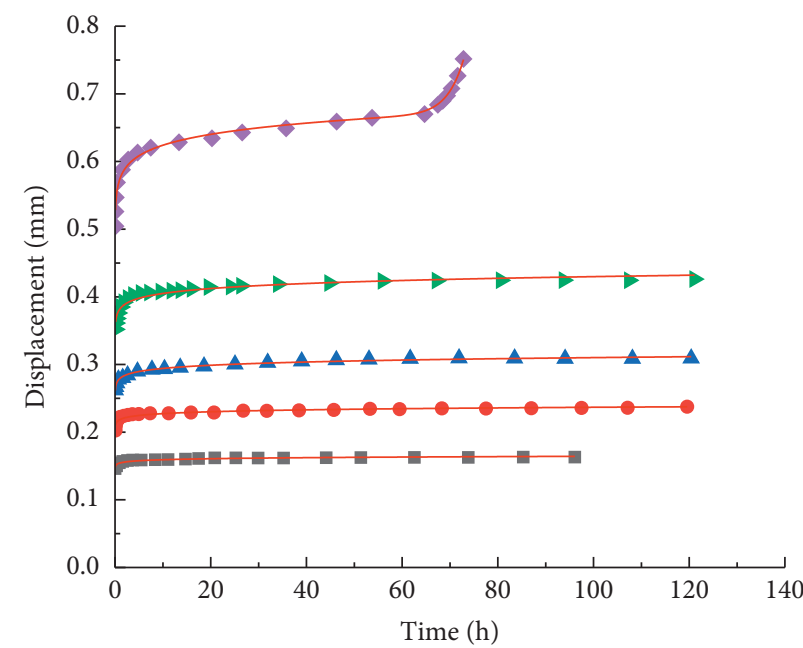

- Creep test data at shear stress of $5.084 \mathrm{MPa}$

- Creep test data at shear stress of $8.132 \mathrm{MPa}$

- Creep test data at shear stress of $11.180 \mathrm{MPa}$

- Creep test data at shear stress of $14.228 \mathrm{MPa}$

- Creep test data at shear stress of 17.276 MPa Fitting curve

Figure 6: Test data and fitting curve.

TABLE 1: Creep parameter identification results.

\begin{tabular}{lccccrr}
\hline Shear stress $(\mathrm{MPa})$ & $G(\mathrm{MPa})$ & $\eta\left(\mathrm{MPa} \cdot \mathrm{mm}^{-1} \cdot \mathrm{h}\right)$ & $\xi_{1}\left(\mathrm{MPa} \cdot \mathrm{mm}^{-1} \cdot \mathrm{h}^{\beta}{ }_{1}\right)$ & $\beta_{1}$ & $\xi_{2}\left(\mathrm{MPa} \cdot \mathrm{mm}^{-1} \cdot \mathrm{h}^{\beta}{ }_{2}\right)$ & $\beta_{2}$ \\
\hline 5.084 & 132.366 & $2.869 \times 10^{20}$ & 44.301 & 0.018 & & 0.9958 \\
8.132 & 135.856 & $2.108 \times 10^{25}$ & 51.949 & 0.024 & 0.9954 \\
11.180 & 138.087 & $5.454 \times 10^{25}$ & 57.345 & 0.031 & 0.9967 \\
14.228 & 139.375 & $7.411 \times 10^{27}$ & 51.804 & 0.034 & 0.9943 \\
17.276 & 168.487 & $4.476 \times 10^{18}$ & 37.525 & 0.043 & $2.101 \times 10^{16}$ & 13.605 \\
\hline
\end{tabular}

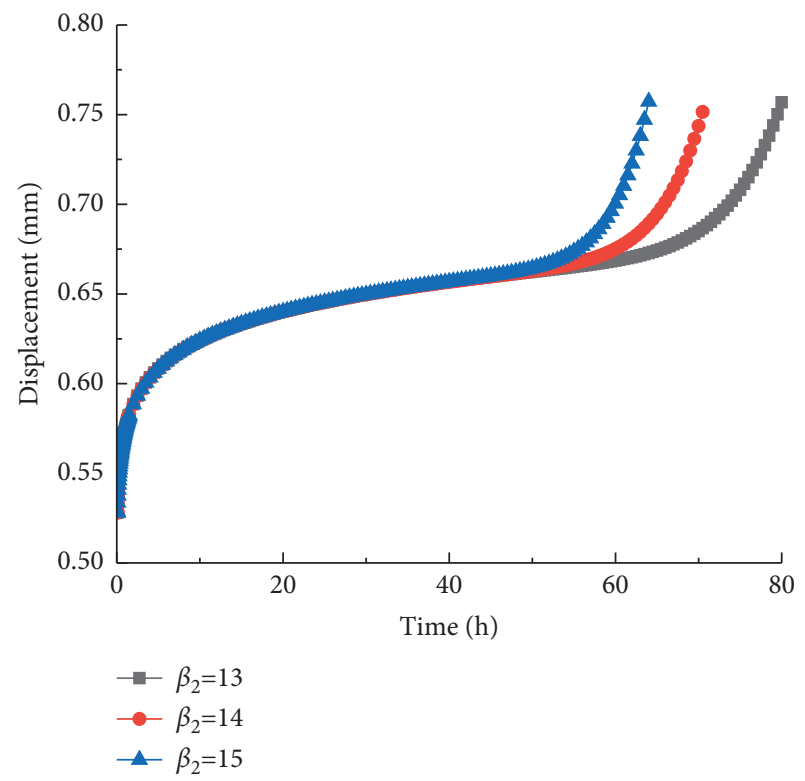

Figure 7: Creep curves under different fractional orders.

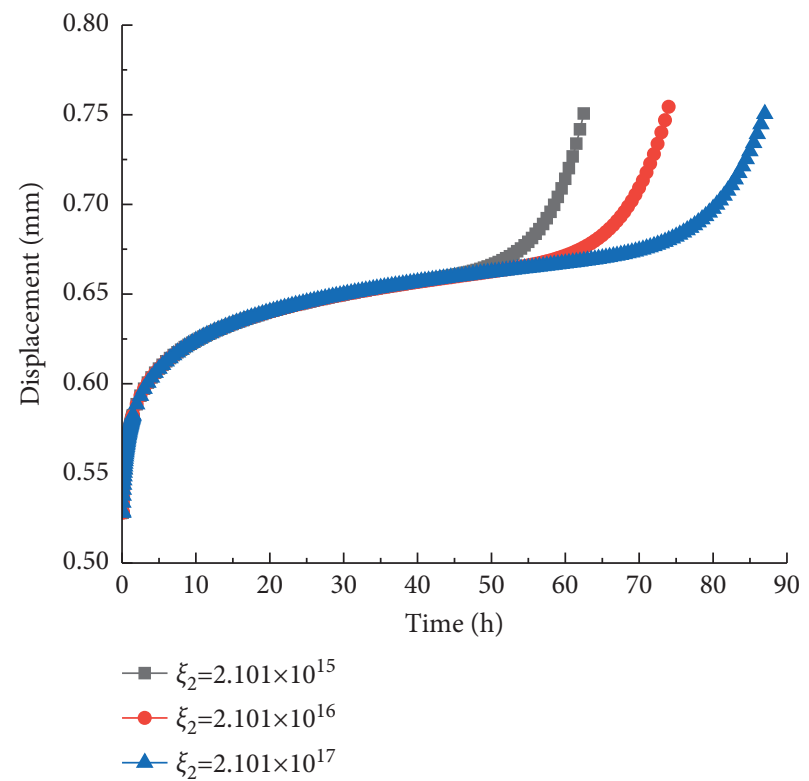

Figure 8: Creep curves under different viscoelastic coefficients. 
$\xi_{2}$. It can be seen from Figure 8 that with the gradual increase in viscoelastic coefficient $\xi_{2}$, it takes more time for rock to have viscoelastic-plastic deformation, and the time for accelerated creep of rock is delayed.

\section{Conclusions}

Based on fractional calculus theory, this paper constructs a nonlinear creep model of rock and verifies the model. The main conclusions are as follows:

(1) Based on fractional calculus theory, a nonlinear viscoelastic-plastic creep model is constructed by combining the fractional creep elements $\left(\beta_{1}\right.$ and $\beta_{2}$ orders), spring elements $(\beta=0)$, and viscous elements $(\beta=1)$. The model has fewer components and fewer parameters and can describe the characteristics of each rock creep stage.

(2) By using the nonlinear curve fitting of the Origin software and the Levenberg-Marquardt optimization algorithm, the creep test data are fitted and compared. It is concluded that the fitting curve is in good agreement with the experimental data, which shows the rationality and applicability of the nonlinear viscoelastic-plastic creep model based on fractional calculus. The model has certain theoretical significance and engineering application value for the long-term stability research of related projects.

(3) Through the sensitivity analysis of the fractional order $\beta_{2}$ and viscoelastic coefficient $\xi_{2}$, their influence law on the rock creep process is obtained.

\section{Data Availability}

The data used to support the findings of this study are included within the article.

\section{Conflicts of Interest}

The authors declare that they have no conflicts of interest.

\section{Acknowledgments}

This research was financially supported by the National Natural Science Foundation of China under grant nos. U1802243 and 41672317, in part by the Hubei Province Technical Innovation Special (Major Project) Project under grant no. 2017ACA184, and in part by the Major Science and Technology Projects of WUST Cultivate Innovation Teams under grant no. 2018TDX01.

\section{References}

[1] G. Peng, Z. Q. Chen, and J. R. Chen, "Research on rock creep characteristics based on the fractional calculus meshless method," Advances in Civil Engineering, vol. 2018, Article ID 1472840, 6 pages, 2018.

[2] B. Hu, P. Z. Pan, W. W. Ji, S. T. Miao, D. C. Zhao, and T. b. Yao, "Study on probabilistic damage constitutive relation of rocks based on maximum-entropy theory," International
Journal of Geomechanics, vol. 20, no. 2, pp. 1-10, Article ID 06019018, 2020.

[3] B. Bai, R. Zhou, G. Q. Cai, W. Hu, and G. C. Yang, "Coupled thermo-hydro-mechanical mechanism in view of the soil particle rearrangement of granular thermodynamics," Computers and Geotechnics, vol. 137, no. 8, Article ID 104272, 2021.

[4] H. Tang, D. P. Wang, and Z. Duan, "New Maxwell creep model based on fractional and elastic-plastic elements," Advances in Civil Engineering, vol. 2020, Article ID 9170706, 11 pages, 2020.

[5] B. Hu, J. Li, J. Sheng, and Z. Ye, "Crack cause in the high slope of Chinese ancient copper mine relics: a three-dimensional non-linear finite difference analysis," IEEE ACCESS, vol. 8, pp. 13987-13997, 2020.

[6] J. Sun, "Rock rheological mechanics and its advance in engineering applications," Chinese Journal of Rock Mechanics and Engineering, vol. 26, no. 6, pp. 1081-1106, 2007.

[7] B. Bai, Q. K. Nie, Y. K. Zhang, X. L. Wang, and W. Hu, "Cotransport of heavy metals and $\mathrm{SiO}_{2}$ particles at different temperatures by seepage," Journal of Hydrology, vol. 597, Article ID 125771, 2021.

[8] S.-Q. Yang, P. Xu, Y.-B. Li, and Y.-H. Huang, "Experimental investigation on triaxial mechanical and permeability behavior of sandstone after exposure to different high temperature treatments," Geothermics, vol. 69, pp. 93-109, 2017.

[9] Q. Zhang, Z. P. Song, J. B. Wang, Y. W. Zhang, and T. Wang, "Creep properties and constitutive model of salt rock," Advances in Civil Engineering, vol. 2021, Article ID 8867673, 29 pages, 2021.

[10] B. Hu, A. N. Cui, K. Cui, Y. Liu, and J. Li, "A novel nonlinear creep model based on damage characteristics of mudstone strength parameters," PLOS ONE, vol. 16, no. 6, pp. 1-17, Article ID e0253711, 2021.

[11] R. Hou, K. Zhang, J. Tao, X. Xue, and Y. Chen, "A nonlinear creep damage coupled model for rock considering the effect of initial damage," Rock Mechanics and Rock Engineering, vol. 52, no. 5, pp. 1275-1285, 2019.

[12] J. Wang, B. Hu, J. Chang, W. P. Wang, and H. L. Li, "Case studies and evaluation of green mining considering uncertainty factors and multiple indicator weights," Geofluids, vol. 2020, Article ID 8893224, 15 pages, 2020.

[13] H. Lin, X. Zhang, Y. X. Wang et al., "Improved nonlinear nishihara shear creep model with variable parameters for rock-like materials," Advances in Civil Engineering, vol. 2020, Article ID 7302141, 15 pages, 2020.

[14] R.-l. Shan, Y. Bai, Y. Ju, T.-y. Han, H.-y. Dou, and Z.-1. Li, "Study on the triaxial unloading creep mechanical properties and damage constitutive model of red sandstone containing a single ice-filled flaw," Rock Mechanics and Rock Engineering, vol. 54, no. 2, pp. 833-855, 2021.

[15] H. Li, N. T. William, J. Daemen, J. Zhou, C.-k. Ma, and C. K. Ma, "A power function model for simulating creep mechanical properties of salt rock," Journal of Central South University, vol. 27, no. 2, pp. 578-591, 2020.

[16] P. Cao, Y. D. Wen, Y. X. Wang, H. P. Yuan, and B. X. Yuan, "Study on nonlinear damage creep constitutive model for high-stress soft rock," Environmental Earth Sciences, vol. 75, pp. 1-8, 2016.

[17] K. Cui, B. Hu, A. N. Cui, J. Li, E. J. Wei, and Z. Zhang, “An extended super/subloading surface model for soft rock considering structure degradation," PLOS ONE, vol. 16, no. 10, pp. 1-16, Article ID e0258813, 2021. 
[18] L. Yang and Z.-d. Li, "Nonlinear variation parameters creep model of rock and parametric inversion," Geotechnical \& Geological Engineering, vol. 36, no. 5, pp. 2985-2993, 2018.

[19] Z.-y. Wang, J. Xu, Y.-p. Li, and Y. Wang, "Rheological damage FEA of hydro-mechanical coupling for rock mass," Journal of Central South University of Technology, vol. 14, no. S1, pp. 324-328, 2007.

[20] B. Hu, E. J. Wei, J. Li, X. Zhu, K. Y. Tian, and K. Cui, "Nonlinear creep model based on shear creep test of granite," Geomechanics and Engineering, vol. 27, no. 5, pp. 527-535, 2021.

[21] Y. Zhao, Y. Wang, W. Wang, W. Wan, and J. Tang, "Modeling of non-linear rheological behavior of hard rock using triaxial rheological experiment," International Journal of Rock Mechanics and Mining Sciences, vol. 93, pp. 66-75, 2017.

[22] W. Y. Xu, S. Q. Yang, and W. J. Chu, "Nonlinear viscoelastoplastic rheological model (hohai model) of rock and its engineering application," Chinese Journal of Rock Mechanics and Engineering, vol. 25, no. 3, pp. 433-447, 2006.

[23] C. C. Xia, X. D. Wang, C. B. Xu, and C. S. Zhang, "Method to identify rheological model by unified rheological model theory and case study," Chinese Journal of Rock Mechanics and Engineering, vol. 27, no. 8, pp. 1594-1600, 2008.

[24] Q. Y. Zhang, W. D. Yang, J. G. Zhang, and C. H. Yang, "Variable parameters-based creep damage constitutive model and its engineering application," Chinese Journal of Rock Mechanics and Engineering, vol. 28, no. 4, pp. 732-739, 2009.

[25] X. Wang, B. Hu, H. Tang, X. Hu, J. Wang, and L. Huang, "A constitutive model of granite shear creep under moisture," Journal of Earth Sciences, vol. 27, no. 4, pp. 677-685, 2016.

[26] B. Hu, S.-q. Yang, and P. Xu, "A nonlinear rheological damage model of hard rock," Journal of Central South University, vol. 25, no. 7, pp. 1665-1677, 2018.

[27] D. S. Yin, J. J. Ren, C. L. He, and W. Chen, "A new rheological model element for geomaterials," Chinese Journal of Rock Mechanics and Engineering, vol. 26, no. 9, pp. 1899-1903, 2007.

[28] B.-R. Chen, X.-J. Zhao, X.-T. Feng, H.-B. Zhao, and S.-Y. Wang, "Time-dependent damage constitutive model for the marble in the Jinping II hydropower station in China," Bulletin of Engineering Geology and the Environment, vol. 73, no. 2, pp. 499-515, 2014.

[29] J. S. Liu, H. W. Jing, B. Meng et al., "Fractional-order creep model for soft clay under true triaxial stress conditions," Arabian Journal of Geosciences, vol. 834, pp. 1-13, 2020.

[30] M. Liao, Y. Lai, E. Liu, and X. Wan, "A fractional order creep constitutive model of warm frozen silt," Acta Geotechnica, vol. 12, no. 2, pp. 377-389, 2017.

[31] Y. Gao and D. Yin, "A full-stage creep model for rocks based on the variable-order fractional calculus," Applied Mathematical Modelling, vol. 95, pp. 435-446, 2021.

[32] P. Huang, J. Zhang, N. Jean Damascene, C. Dong, and Z. Wang, "A fractional order viscoelastic-plastic creep model for coal sample considering initial damage accumulation," Alexandria Engineering Journal, vol. 60, no. 4, pp. 3921-3930, 2021.

[33] G. J. Xiang, D. S. Yin, C. X. Cao, and Y. F. Gao, “Creep modelling of soft soil based on the fractional flow rule: simulation and parameter study," Applied Mathematics and Computation, vol. 403, pp. 1-10, 2021.

[34] Y. Peng, J. Zhao, and Y. Li, "A wellbore creep model based on the fractional viscoelastic constitutive equation," Petroleum Exploration and Development, vol. 44, no. 6, pp. 1038-1044, 2017.
[35] H. Xu and X. Jiang, "Creep constitutive models for viscoelastic materials based on fractional derivatives," Computers \& Mathematics with Applications, vol. 73, no. 6, pp. 1377-1384, 2017.

[36] Q. Wu and J. H. Huang, Fractional Calculus, Tsinghua University Press, Beijing, China, 2016.

[37] M. F. Wang, B. Hu, H. F. Jiang, G. J. Ou, and L. Gan, "Experiment and model investigation on shear rheological mechanical properties of granite," Journal of Central South University, vol. 45, no. 9, pp. 3111-3120, 2014. 